\title{
STAATKUNDIGE GESCHIEDENIS VAN CURAÇAO
}

(De Curaçaosche begrooting voor 1940)

$$
\begin{gathered}
\text { II (slot) } \\
\text { DOOR }
\end{gathered}
$$

\section{B. DE GAAY FORTMAN}

Zeer veel begrootingsarbeid is in het zittingsjaar 1939/40 afgedaan. Het slot der rekening over 1936 is vastgesteld met een overschot van $f 56.000$.- , dat ten gunste van het Pensioenfonds komt. Voor 1937 en 1938 zijn regularisatie-voorstellen ingediend, die tot geenerlei wisseling van gedachten hebben aanleiding gegeven. De begrooting voor 1940 is vastgesteld en alweer gewijzigd; die voor 1939 is bij een 2de en een 3de aanvullende begrooting gewijzigd; alleen van de 2 de staan mij de notulen der openbare beraadslaging ten beschikking. Daarvan is wel een en ander te vertellen.

Onder de onderwerpen, die door verscheidene leden bij wege van algemeene beschouwingen ter sprake zijn gebracht behooren landsverdediging, politie, woningsvraagstuk en onderwijs. Wat het eerste onderwerp betreft, heeft de heer Rustige de gedachte naar voren gebracht van de instelling van een Imperialen defensieraad, die van een centraal punt uit de geheele verdediging van ,groot Nederland" zou regelen, een denkbeeld, dat, zooals hij zei, in Nederland door ,,allerhoogste militaire autoriteiten" is voorgestaan. Wat de defensie-uitgaven voor Curaçao aangaat, was het den heer Rustige er vooral om te doen, te weten waaraan het gebiedsdeel toe is. Terecht m.i., vooral als men bedenkt, dat het hier een door Curaçao onverplicht op zich genomen last betreft. Behalve de $f 240.000$. - als bijdrage aan de staatsbegrooting werd nu $f$ 75.000.- als ,aandeel" in de kosten van de verdedigingswerken gevraagd. Waarvan is dit een aandeel, en waartoe verplicht ons de toestemming tot deze post voor de toekomst? was de vraag waarop geen antwoord kwam.

De heer Rustige heeft inlichtingen gevraagd over het bestaan

$$
-321-
$$

West-Indische Gids XXII 
van een voornemen om Nederlandsche dienstplichtigen zoo noodig in Curaçao in werkelijken dienst op te roepen, en de heer Bichon van IJsselmonde heeft dit ongewenscht genoemd met het oog op het bestaande arbeidstekort.

Over onderwijsaangelegenheden is geruimen tijd gesproken. Gebrek aan schoolruimte is een nijpend vraagstuk, waarin bij deze begrooting slechts ten deele werd voorzien. En de voorzitter bracht met name de belangen van een voorbereidend onderwijs ter sprake. Voor woningbouw was $f$ 200.000.- aangevraagd als voorschotten voor particulieren woningbouw, wat van meer dan één zijde te weinig werd geacht. Op het gebied van de politie is dit het verschil tusschen bestuur en een deel der Staten, dat het bestuur uitbreiding van burger- èn militaire politie noodig acht, maar de eerste voorhands heeft teruggenomen met de bedoeling militaire politie bij de burgerpolitie te detacheeren. terwijl eenige Statenleden aan de uitbreiding der burgerpolitie de voorrang zouden willen toekennen en voor de landsverdediging mariniers laten uitkomen. Een eigenaardige staatsrechtelijke figuur deed zich daarbij voor, toen de heer Rustige uitsprak, dat een amendement in dezen geest groote kans van aaneming zou hebben, wanneer tenminste niet daardoor de begrooting naar Nederland zou moeten, want die consequentie zou wel geen meerderheid vinden. Nu zou die kans waarschijnlijk wel groot geweest zijn, want het bestuur acht uit defensiebelang de versterking van de militaire politie noodig. De heer Bichon van IJsselmonde heeft instemming betuigd met het gewijzigd bestuursvoorstel en de opmerking gemaakt, dat het nu maar eens uit moest zijn met het gepraat tegen de militaire politie, en hulde gebracht aan haar leiding.

De heer Bichon van IJsselmonde wees nog op eenige geldelijke vraagstukken. De vaste lasten zijn weer met 1 millioen gestegen en tot 8 millioen geklommen, dat kon weleens vastloopen. Als oorzaak van dit veel te hooge bedrag noemde hij het te groote bestuursapparaat met zijn te groot aantal ambtenaren, die de bestuursmolen maar langzaam doen malen. Men vergeet, dat de bestuursafdeelingen geen ministerieele departementen zijn, en haar hoofden allen adviseurs van den gouverneur, die alleen de leiding heeft. De spreker had ook een oplossing, nl. een tweede man onder den gouverneur, die de uitwerking der door dezen aangegeven lijnen in de hand houdt en beslissende macht heeft. Deze tweede man zou ook als verdediger van het bestuursbeleid in de Staten op zijn plaats zijn. 
De heer Maal was zeer ontstemd: nòg geen les in het Papiamentsch voor uitgezonden ambtenaren, nòg achterstelling van Curaçaonaars, een slechte verstandhouding tusschen Bestuur en Staten, miskenning van het budgetrecht der Staten, veronachtzaming van in de Staten uitgesproken wenschen; moet men reeds spreken van een totalitair bestuurd Curaçao?

De administrateur van financiën heeft als bestuursgemachtigde iets over eenige der besproken onderwerpen gezegd. Alleen wat hij zei over het door den heer Maal aangevoerde tegen het doen van uitgaven zonder dat daarvoor gelden zijn toegestaan, is vermeldenswaard. Ter kenschetsing. Het komt hierop neer. Het bestuur ontleent zijn bevoegdheid om uitgaven te doen niet aan de begrooting maar aan zijn recht en plicht om te regeeren. Vaststelling van een begrooting is machtiging geven tot het doen van uitgaven. Ook zonder die machtiging kan het bestuur uitgaven doen; daartoe moet dan achteraf machtiging worden verleend (In de loop der vergadering had mr. Da Costa Gomez gelegenheid te zeggen, dat hij het met dit standpunt niet eens is). Het beste is 't, vooraf de goedkeuring der Staten te vragen, maar ook in niet-spoedeischende gevallen gaat dit dikwijls niet.

Bij de behandeling der artikelen, toen de heer Bichon van IJsselmonde voorstelde $f 49.000$. - toe te staan voor den bouw en inrichting van een school voor de Vereeniging voor christelijk onderwijs en opvoeding, heeft de administrateur van financiën zijn oude standpunt, of liever het oude bestuursstandpunt, over het recht der Staten om, zonder instemming van het bestuur, posten op de begrooting te verhoogen of nieuwe erop te brengen, gehandhaafd. Dit komt hierop neer: budgetrecht is controlerecht, het recht om het bestuur in zijn uitgaven te beperken, niet om het uitgaven op te dringen, Wat de zaak zelf betreft, moest de heer Bichon van IJsselmonde zich verblijden met een doode musch: het bestuur onderschreef de wenschelijkheid van deze christelijke school, maar meende, dat andere uitgaven, bijv. de voorziening in het tekort van schoolruimte voor de bestaande scholen, diende voor te:gaan.

Even weinig gelukkig was hetzelfde Statenlid met een voorstel om $f$ 50.000. - uit te trekken als voorschot voor woningbouw aan de Protestantsche vereeniging van liefdadigheid en maatschappelijk werk. Hiertegen werd van bestuurszijde ook aangevoerd, dat zulke voorschotten alleen werden gegeven aan vereenigingen, die alleen woningbouw beoogen als waarborgen voor het besteden der gelden voor dat doel. 
Andere leden waren met eenige amendementen tot vermindering of afvoering van bepaalde posten gelukkiger, doordat hetzij het bestuur die overnam, hetzij zij ondanks verzet van het bestuur aangenomen werden. In het geheel betrof dit $f 52.000$.t.w. $f$ 14.000.- voor een stedenbouwkundige, $f 25.000$ - - voor verbouwing van een politiebureau, $f$ 13.000.- in verband met de exploitatie van Klein St. Martha.

Ten slotte kwam er half December 1939 een derde aanvullende begrooting voor het loopende jaar. Daarop kwamen $f$ 45.000.voor onderwijsuitgaven, ruim $f$ 100.000.- voor luchtbescherming op Curaçao en Aruba, $f$ 165.000.- voor voedselvoorziening, terwijl voor openbare werken tot een bedrag van twee ton werd afgevoerd en $f$ 85.000.- opgebracht. Van de kleinere, posten moet genoemd worden een bijdrage van $f$ 1000.- voor het Koloniaal instituut, dat in de toelichting ,ook voor Curaçao van economisch, sociaal en cultureel belang" wordt geacht. De schriftelijke behandeling had weinig om 't lijf. Uit de in het Publicatieblad afgekondigde desbetreffende beschikking blijkt, dat van een bedrag van $f$ 165.000.- is afgevoerd $f 30.000$. - voor een geldleening ten behoeve van de aanschaffing van een vischkotter.

En nu dan de begrooting voor 1940. De uitgaven werden geraamd op $11 \frac{1}{2}$ millioen, d.i. 2 millioen meer, dan oorspronkelijk voor 1939 geraamd was, maar $1 \frac{1}{2}$ millioen minder dan $\mathrm{de}^{t}$ $f$ 13.000.000.- , ten slotte voor dat jaar geraamd. Aan ontvangsten werd bijna 12 millioen voor ' 40 geraamd, zoodat er een overschot van 3 ton zou zijn.

Aan de openbare behandeling zijn na een zeer uitvoerige schriftelijke voorbereiding, waarbij ook verscheidene détailpunten naar voren gebracht zijn, twee avonden gewijd. Daarbij zijn ongetwijfeld groote lijnen getrokken met name door de heeren mr. Da Costa Gomez en Rustige. Het is wel van belang hierbij even stil te staan.

Had de heer Maal over de verhouding tusschen Bestuur en Staten minder gunstig geoordeeld, de heer Da Costa Gomez noemde de samenwerking ,,bevredigend”. Er liggen echter z.i. moeilijkheden voor een goede vervulling van de taak der Staten in de staatsregeling, die onjuiste en onvoldoende regelingen bevat en met begrippen werkt, die in het Curaçaosche staatsrecht niet scherp omlijnd zijn. Zoolang de staatsregeling niet herzien is, moeten publiekrechtelijke gewoonten in deze leemten en onjuistheden voorzien ten behoeve van den geregelden en ongestoorden arbeid en het gezag der Staten. 
Welke die gebreken en leemten in de Curaçaosche staatsregeling zijn, heeft mr. Da Costa Gomez niet gezegd; alleen werd de autonomie van Curaçao genoemd in de staatsregeling onvoldoende omlijnd; ook niet welke de staatsrechtelijke gedragingen zijn, die, eerlang publiekrechtelijke gewoonten geworden, moeten dienen om voorloopig in die niet genoemde moeilijkheden te voorzien; daaronder kan ten minste moeilijk gerekend worden de onverplichte bijdrage in de kosten van verdediging van Curaçao. Het verdere betoog van dit Statenlid ging uit van de stelling: Bestuur en Staten moeten erop bedacht zijn, zoo min mogelijk het Opperbestuur in de behartiging van Curaçaosche aangelegenheden te betrekken. Verkeerd is het, dat volgens de staatsregeling de gouverneur aan aanwijzingen des konings gebonden is. Niettemin erkende de spreker, dat het opperbestuur waardeering verdiende voor de wijze, waarop het met de Staten in gedachtenwisseling wilde treden over een ontworpen algemeenen maatregel van bestuur (bedoeld zal zijn de reeds eerder genoemde toelating en vestiging in - en uitzetting uit Curaçao.) Wat betreft het recht van amendement van de Staten ten aanzien van begrootingsontwerpen, bleek de heer Da Costa Gomez het standpunt van het bestuur, dat verhooging van de uitgaven aldus niet geschieden kan, niet te deelen.

Mr. Bichon van IJsselmonde heeft aanstonds verzet aangeteekend tegen de opvatting van zijn ambtgenoot omtrent de verhouding tusschen Opperbestuur en Bestuur en uitgesproken, dat hij vertrouwde, dat het Opperbestuur te allen tijde die aanwijzingen zou geven, die het noodig zou achtten in het belang van Curaçao. De bestuursgemachtigde wilde, ,rijp beraad en ruggespraak met den Gouverneur" alvorens op deze vraagstukken terug te komen.

De heer Rustige, die met genoegen naar het college staatsrecht van den heer Da Costa Gomez had geluisterd, heeft zelf een college onderwijsvernieuwing gegeven. Het streven der 19de eeuw naar kennis en wetenschap, dat de maatschappij dompelde in geestelijke anarchie, zedelijke verwildering, oorlogen, werkeloosheid, heeft een reactie opgewekt, die de jeugd wil opvoeden tot verantwoordelijkheidsbesef. tot een door het christendom gedragen gemeenschap op de pijlen van naastenliefde en verdraagzaamheid. Deze gedachten, ontleend aan het maandschrift der Vereeniging voor vernieuwing van opvoeding en onderwijs, en het werk en streven van Nederlandsche deskundigen, onder welke hij den in Curaçao niet onbekenden heer Welling noemde, leidde 
den spreker tot zijn meening, dat ook Curaçao in den weg van besnoeiing eigen richting dient te zoeken, passend bij de behoeften van Curaçao. Is de inspecteur bereid in die richting mee te werken, vroeg de heer Rustige, met inschakeling van land- en tuinbouwonderwijs en uitbreiding van dat in lichamelijke opvoeding?

Ook tegen deze opvattingen is de heer Bichon van IJsselmonde in verzet gekomen. In de eerste plaats vroeg hij, of de Curaçaosche onderwijswetgeving niet ruimte laat voor toepassing der denkbeelden van den heer Rustige, zoodat deze meer een zaak voor de schoolbesturen dan voor het gouvernement is. En wat de zaak zelf betreft vreesde hij, dat eerder dan besnoeiing, verhooging van het peil van het onderwijs zou noodig zijn om de leerlingen der Curaçaosche scholen gelijkwaardig te doen zijn met die der omringende landen.

De onderwijsinspecteur heeft als bestuursgemachtigde zeer uitvoerig den heer Rustige geantwoord. Z.i. ligt het niet op den weg van het bestuur voor te gaan in de geschetste richting, omdat in Curaçao het openbaar onderwijs slechts weinig omvangrijk is. De gedachten van den heer Rustige latende voor wat zij zijn, heeft de heer Goslinga erop gewezen, dat in Nederland het genoemde streven van paedagogen en inspecties met name in de kringen van het Roomsch-katholieke en Protestantschchristelijke onderwijs weinig instemming geniet. Het bleek wel, dat tot verwezenlijking van deze gedachten van den inspecteur weinig aandrang zal uitgaan.

Belangrijk is ook hetgeen gezegd werd over de landstaal. Deze is meer spreek- dan schrijftaal en er bestaan geen vaste regelen voor de schrijfwijze. Neem het woord koenoekoe, dat men ook cunucu schrijven kan en zoo geschiedt het ook. Ds. Eybers heeft voor zijn vertaling van het Nieuwe testament een stelsel opgebouwd, waarin cunucu past; de missie schrijft, naar ik meen, koenoekoe, en de heer Maal vindt, dat het cunucu moet zijn. M.i. ligt de zaak zoo, dat beide richtingen (er zijn daarin nog meer afwijkingen) begrijpelijkerwijs bedoelen een phonetische schrijfwijze en dat hij, die voor Nederlandsche oogen schrijft, met cunucu niet de juiste uitspraak verkrijgt, terwijl koenoekoe voor niet-Nederlandsche oogen waarschijnlijk onuitsprekelijke klankformaties opwekt. Men kan natuurlijk ook de afleiding der woorden als grondslag voor de spelling nemen, maar dan krijgt men een hopelooze verwarring. Dan komt naast cunucu bijv. stoel te staan. Daarom zou ook ik aan een phonetische schrijf- 
wijze de voorkeur willen geven en dan zou men kunnen zeggen, dat een Nederlandsch bestuur de Nederlandsch-phonetische spelling heeft te volgen.

$\mathrm{Nu}$ gaat men echter een woordenboek maken zonder een officieele schrijfwijze vast te stellen. Dat behoeft geen weggegooid geld te zijn, als de samenstellers maar een vast stelsel volgen; dan kan dit woordenboek wetenschappelijke waarde hebben en voor wetenschappelijk geschoolden nut doen, maar of het praktisch is en of de eenvoudige het woordenboek zal kunnen raadplegen is een andere zaak.

Het Papiamentsch is ook in anderen zin onderwerp van bespreking geweest. De heer Da Costa Gomez heeft ervoor gepleit, dat het onderwijs aan de landstaal de noodige aandacht zou wijden op de wijze, waarop in Nederland kennis van een streektaal bij lezen en Nederlandsche taal onderwezen kan worden. De heer Rustige, die verklaarde de landstaal niet te kennen (wel eenigzins ontstellend!), zou haar als voertaal in de eerste tweeleerjaren willen gebruiken en van de tweede helft van het vierde leerjaar af zou dan het Nederlandsch de voertaal moeten zijn. Hoe het daartusschen zou moeten zijn, als het onderwijs in de Nederlandsche taal naar voren moet komen, zei de spreker niet. Het uitvoerige antwoord van den onderwijsinspecteur bracht geen oplossing. De wet verbiedt zoo het een als het ander. Men zou echter ook, als er in de gedachten van de heeren Da Costa Gomez en Rustige iets goeds ligt, de wet kunnen veranderen. Dat godsdienstonderwijs in het Papiamentsch gegeven wordt van wege de kerk zal waarschijnlijk voor geen van beide sprekers iets nieuws of de vervulling van hun wensch geweest zijn.

Van de talrijke - meer en minder belangrijke - onderwerpen, die verder ter sprake zijn gekomen, noem ik er enkele.

De salarisregeling der ambtenaren dreigt tot een geschil tusschen Bestuur en Staten te leiden. Hierbij speelt het vraagstuk der huurprijzen en dat van den levensstandaard een rol, die het probleem eenige gelijkenis geeft met dat van een vicieuzen cirkel, en de oplossing ervan verwantschap doet toonen met het vinden van den kwadratuur van den cirkel.

Uit een rede van het Statenlid Arends bleek, dat Aruba nog vele en groote wenschen heeft: naast het havenvraagstuk eischen hier o.a. onderwijs, woningbouw en openbare werken in velerlei vorm de aandacht van het bestuur.

De heer Maal nam Openbare werken voor zijn rekening. Figuurlijk gesproken natuurlijk, want hij toonde met een treffend voor- 
beeld aan, dat dit departement erg duur werkt. Hij wees erop, dat er van 1922-1939 zeventien directeuren van Openbare werken versleten zijn. Ook dit weer in figuurlijken zin, want zijn klacht was juist, dat ze, nog lang niet versleten, weggingen in plaats van te blijven.

Natuurlijk hebben ook de politie en de landswatervoorzieningsdienst aandacht gevraagd.

Voor de bovenwindsche eilanden is met name hun afgevaardigde, de heer Plantz, in het krijt getreden. Na 31 jaar zijn de douanerechten eindelijk afgeschaft; de heer Plantz hoopte ook op afschaffing van den landbouwkundigen dienst op die eilanden, die - althans op St. Maarten en Saba - tot nu toe slechts geld heeft weggegooid naar zijn inzien.

Dezelfde afgevaardigde heeft de aandacht gevestigd op de hooge kosten van den luchtvaartdienst, die voor twee jaren $f$ 400.000. - beloopen. Zijn vraag, of het bestuur deze kosten gerechtvaardigd acht, is bevestigend beantwoord, maar heeft den heer Plantz niet weerhouden zijn tegenstem uitdrukkelijk te doen aanteekenen, wat betreft de voorgestelde verhooging der bijdrage aan de K.L.M.

Van bestuurszijde werd de heer Maal zeer verblijd met de mededeeling,dat bij gelijke bevoegdheid aan het landskind de voorkeur zal worden gegeven, als het gaat om de aanstelling van arbeidskrachten. Nochtans was het niet de eerste maal, dat deze voor de hand liggende verzekering gegeven werd.

Breed is nog van gedachten gewisseld over steun aan het grootlandbouwbedrijf, die van verschillende zijden werd noodig geacht naast die aan het kleinbedrijf o.a. op de wijze als met het Helfrichdorp geschiedt, maar de heer Maal had met een desbetreffend amendement geen succes.

8 Februari 1940 diende de gouverneur een aanvullende begrooting 1940 in. Nooit wellicht werd een dergelijk voorstel zoo uitvoerig toegelicht. Twee weken later reeds verscheen het even gedocumenteerde Voorloopig verslag. Maar van de verdere behandeling weet men hier in Nederland niets. Om het overzicht van het geheel niet te doen uiteenvallen bepaal ik mij nu tot de mededeeling van eenige richtlijnen, die bij de samenstelling van het ontwerp gegolden hebben, en tot de vermelding van eenige zeer bijzondere onderdeelen.

De gouverneur deelt in de memorie van toelichting mee, dat hij in de eerste plaats heeft rekening gehouden met de nood- 
zakelijkheid om de gewone uitgaven te verlagen. Tweede richtsnoer is geweest, dat alleen onvermijdelijke kapitaalswerken voor uitvoering in aanmerking zouden moeten komen. En ten derde zijn belangrijke uitgaven als gevolg van de buitengewone omstandigheden moeten worden geraamd.

Op de personeelsuitgaven is een bezuiniging ontworpen, die op den duur ruim $f$ 100.000.- besparing 's jaars zal geven. De kapitaalsuitgaven zijn met $f 600.000$.- verminderd. Daartegenover staan hoogere ramingen wegens prijsstijging van materialen en vrachtprijzen, wegens uitbouw der openbare bedrijven, voor verbetering van de brandweer en de laboratoria van den Gezondheidsdienst. Op onderwijsuitgaven is ruim $f 50.000$. - kunnen bezuinigd worden op een wijze, die het onderwijs ten goede komt, terwijl zonder nieuwbouw kan worden tegemoet gekomen aan de eischen van een christelijk-protestantsch bijzonder onderwijs. Voor de uitgaven der landsverdediging, voedselvoorziening inbegrepen, is bijna 1 millioen meer geraamd, waarvan $f 600.000$. - voor de schutterij en $f 316.000$. - bijdrage aan de rijksbegrooting.

Voor den Landsradiodienst is $f 67.500$ - meer gevraagd en $f 30.000$. - voor het luchtverkeer (in verband met den aanleg van een nieuw vliegveld in Suriname, noodig voor een nieuwe luchtverbinding met Nederland.

Het doet wat vreemd aan, dat de gouverneur in dezen tijd nog gedacht heeft aan de ,urgentie” van een plan voor stadsuitbreiding, al zouden daarmee maar $f 35.000$. - zijn gemoeid. Trouwens een aantal der nieuwe werken, waarvoor - met aankoop van onroerende goederen $-f 388.400$. - is geraamd, zaldoor het verloop der zaken ook wel niet tot stand gekomen zijn.

Van een en ander is het gevolg, dat tegenover $f 1.400 .000$.stijging der uitgaven een verlaging van $f 900.000$.- staat, zoodat het eindcijfer, voor 1940 oorspronkelijk geraamd op $f$ 11.216.519.- - verhoogd wordt tot $f$ 11.703.928.- Een nieuwe raming der middelen heeft een batig verschil van $f$ 837.000.opgeleverd, waarbij ermee rekening gehouden is, dat de aanhangige belastingontwerpen tot stand komen. Bovendien stelt de gouverneur zich voor nog met een vermakelijkheidsbelasting en een weeldebelasting te komen.

Hoewel dit overzicht langer geworden is, dan het pleegt te zijn, maakt het geenszins aanspraak op volledigheid. Ik mag slechts hopen, dat het een inzicht geeft in den nieuwen toestand, 
die de Europeesche oorlog in Curaçao in het leven heeft geroepen. En nu weten wij nog niets van hetgeen sedert April gebeurd is. Dat behoort trouwens tot een nieuw jaaroverzicht. Ik stel mij voor, dat daaraan nog moet voorafgaan een aanvulling van het bovenstaande.

Over Curaçao in de Staten-Generaal behoef ik ditmaal niet te spreken, ik heb dat in de Kroniek van Januari 1940 gedaan wat de Tweede Kamer betreft, en de behandeling in de Eerste Kamer is van uiterst weinig belang geweest.

Amsterdam 23 Augustus 1940. 